\title{
Myoepithelioma-like tumor of the vulvar region: a case report in China and review of the literature
}

Yan Xu' ${ }^{1,2}$, Hui Gao ${ }^{1,2}$ and Jin-Li Gao ${ }^{1,2^{*}}$

\begin{abstract}
Background: Myoepithelioma-like tumor of the vulvar region (MELTVR) is a recently described mesenchymal neoplasm which typically arising in vulvar regions of adult women.

Case presentation: Here we report a case of a 65-year-old woman who presented with a 6-year history of subcutaneous mass in the vulvar region. The mass had recently increased in size continuously. Histologically, the tumor cells had an epithelioid to spindled shape. Epithelioid tumor cells proliferated singly or in a loosely cohesive manner with myxoid areas, while spindled tumor cells grew in diffuse sheets or storiform arrangements mainly in nonmyxoid areas. Immunohistochemically, the tumor cells were positive for vimentin, epithelial membrane antigen, calponin, and were partially mild to moderate positive for estrogen receptor, but completely negative for S100 protein, glial fibrillary acidic protein, CD34, desmin, SMA and cytokeratin. INI1/SMARCB1 expression was deficient. EWSR1 and FUS genes were intact tested by fluorescence in situ hybridization analysis. Based on these findings, we diagnose this case as MELTVR. The patient remained relapse-free after the lesion was widely excised during 8 months follow-up.
\end{abstract}

Conclusions: This disease should be included in the differential diagnostic list of vulvar tumors with epithelioid to spindled morphology. Recognition of its histopathological features and immunohistochemical reactivity will help to understand the tumor better.

Keywords: Myoepithelioma-like tumor of the vulvar region, MELTVR, vulva, INI1/SMARCB1

\section{Background}

Myoepithelioma-like tumor of the vulvar region (MELTVR) is a soft-tissue neoplasm that is rarely observed in clinical practice; however, its typical characteristics have been described in the literature, including the histological, immunohistochemical and molecular signatures. MELTVR was first described by Yoshida et al. in 2015 [1], who reported nine cases arising from the vulvar region with a uniform INI/SMARCB1- deficient immunohistochemical reactivity. In our report, we present a case of MELTVR that arose in the vulva of a middleage woman, which was initially suspected to be a leiomyoma.

\footnotetext{
*Correspondence: gaojinli.ok@163.com

'Department of Pathology, East Hospital, Tongji University, 1800 Yuntai Road, Pudong New District, Shanghai 200120, China

${ }^{2}$ Central Laboratory, East Hospital, Tongji University, Shanghai, China
}

\section{Case presentation}

A 65-year-old woman presented with 6-year history of subcutaneous nodule in the vulvar region and recently the mass obviously increased creating personal discomfort. She was then admitted to our hospital for treatment. Computed tomography (CT) of the pelvis showed a cystic solid mass (diameter $50 \mathrm{~mm}$ ) in the perianal region, suggesting a benign leiomyoma. The patient had no prior history of malignancy. Then, the patient underwent wide excision. On surgery, one nodule was found to be located in the vulvar muscle space, measuring approximately $45 \mathrm{~mm}$ in maximum diameter. The tumor was well-defined without obvious capsule. No sign of local recurrence or metastatic disease was observed after the initial excision during an eight-months follow-up.

Grossly, the lesion was a well-circumscribed (Fig.1a), solid mass, with areas of translucent quality. On cut section, there was a solid white to gray lobulated nodule, 

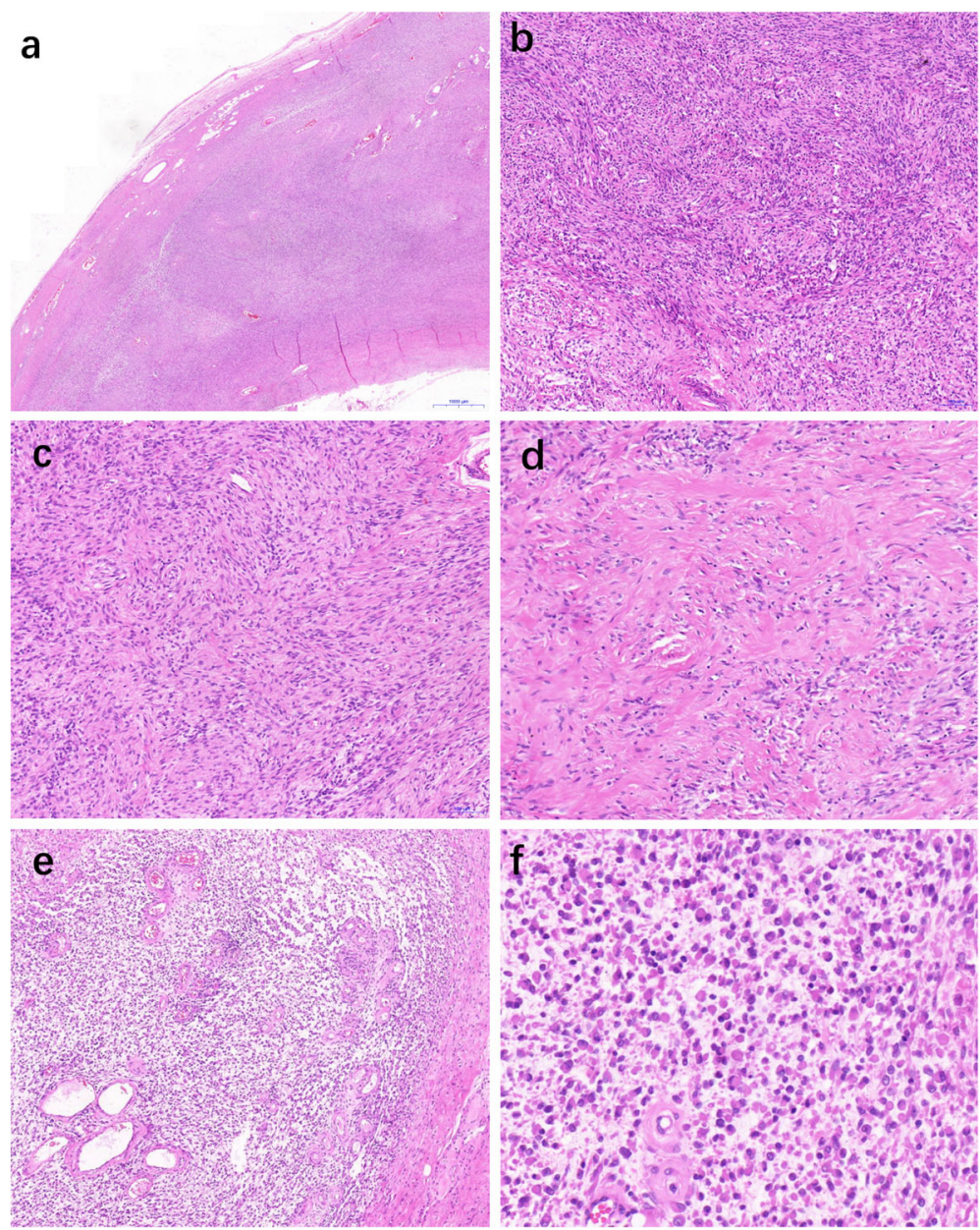

Fig. 1 The tumor was a well-circumscribed nodule, focally encased by a fibrous pseudocapsule (a). In nonmyxoid patterns, the spindle-shaped tumor cells formed storiform arrangements, with a combination of hypocellular and hypercellular areas (b-c). The fibrous area shows deposition of hyalinizing collagen fibers (d). In myxoid patterns, epithelioid tumor cells proliferated singly or in a loosely cohesive reticular manner (e), In high power field, the epithelioid tumor cells resembled rhabdomyoblasts (f)

measuring $5.5 \times 4.0 \times 3.5 \mathrm{~cm}$ in size. Histologically, at low magnification, the tumor was well circumscribed, focally encapsulated, and lobulated. The tumor stroma was relatively hypervascular and comprised a mixture of myxoid and nonmyxoid components, myxoid areas accounted for $20 \%$ of the tumor volume. At high magnification, the lesion was composed of spindle-shaped to epithelioid cells with abundant amphophilic cytoplasm, consisting of vesicular nuclei and small nucleoli. In nonmyxoid area, the tumors cells arranged in storiform pattern (Fig.1b, c) and some areas of tumor stroma was predominantly hyalinized or fibrous (Fig.1d). In myxoid areas, tumors cells grew singly or in a loosely cohesive manner with abundant eosinophilic cytoplasm resembling rhabdomyoblasts (Fig.1e, f). Rhabdomyoblasts-like cells accounted for approximately $80 \%$ of the total cells in the myxoid areas. The nuclear atypia was mild to moderate and mitotic figures were low (up to five mitosis per 50 high-power fields).
Immunohistochemically, the tumor cells were diffusely positive for Vimentin, and partially positive for epithelial membrane antigen (EMA) with at least moderate intensity, which was mainly expressed in epithelioid cells (Fig.2a). Estrogen receptor (ER) was weakly expressed in some tumor cells (Fig.2b). Calponin (clone: CALP and EP63) was positive for both the nucleus and the cytoplasm of the tumor cells (Fig.2c). Focal expression for Bcl-2 and CD99 was observed. The tumor was negative for S100 protein (Fig.2d), cytokeratin (CK), glial fibrillary acidic protein (GFAP), CK7, SOX10, CD31, CD34 (Fig.2e), desmin, MyoD1, myogenin, smooth muscle actin (SMA), CD117, $\beta$-catenin and MUC4. Loss of INI1 protein expression was also confirmed (Fig.2f). The Ki67 index was about 10\%. The results of immunochemical staining were summarized in Table 1.

Using formalin-fixed, paraffin-embedded 4-mm-thick tumor samples, dual-color break-apart fluorescence in situ hybridization (FISH) was used to investigate EWSR1 


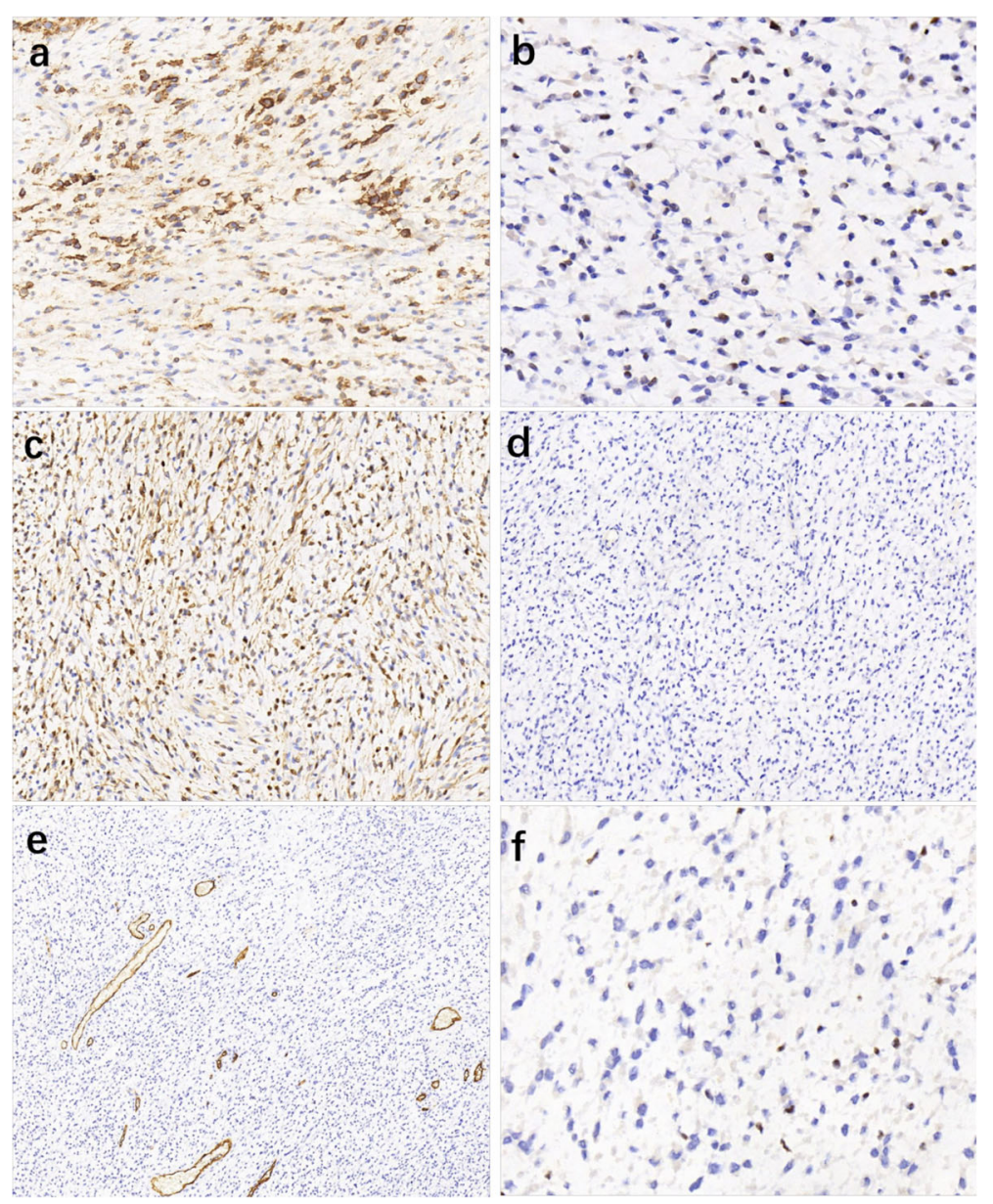

Fig. 2 Immunohistochemical findings most tumor cells were partially and moderate positive for EMA (a), and mild to moderate positive for ER (b). Calponin was expressed both in the cytoplasm and in the nucleus of the tumor cells. (c). The tumor cells were completely negative for S100(d) and CD34 (e). All tumor cells showed no INI1/SMARCB1 expression, while non-neoplastic endothelial cells expressed INI1/SMARCB1 (f)

and FUS1 gene rearrangements. Break-apart probes for EWSR1 (Abbott Molecular Inc., USA) and FUS1 (Abbott Molecular Inc., USA) were used, and no split signals were observed with either probe (Fig.3a, b).

\section{Discussion}

MELTVR is a rare neoplasm. Up to present, eleven cases of MELTVR have been reported in the literature [1-3]. The tumor is not classified according to the 4th edition of WHO classification of Soft Tissue and Bone Tumors [4]. MELTVR represents one of SMARCB1-deficient vulvar neoplasms [5]. Although it is difficult to diagnose the disease due to its rarity, it can be confirmed by the combination of histological and immunohistochemical features. In addition, molecular is also an important tool for differential diagnosis of MELTVRs and other tumors.

Based on the literatures, the clinical manifestation of MELTVR was not specific. Most patients presented with a painless mass or had occasional pain. The clinical diagnosis embraced a wide variety of disease, including solitary fibrous tumor, aggressive angiomyxoma, angiomyofibroblastoma, lipoma, hemangioma, and schwannoma $[1,2]$. In our case, the lesion was originally considered leiomyoma or fibroma. At histology level, broad differential diagnoses need to be considered, including several tumors with loosely cohesive growths of epithelioid or spindle cells in a variable myxoid or hyalinized background. The morphology of this tumor resembles soft tissue myoepitheliomas, particularly those tumors with a myxoid pattern, but the neoplastic cells are negative for S100, GFAP and myogenic markers such as SMA, desmin. At molecular level, most of soft tissue myoepitheliomas harbor EWSR1 gene translocation with a variety of different fusion partners, including EWSR1POU5F1, EWSR1-PBX1, and EWSR1-ZNF444 [6-8]. FUS gene rearrangements have also been reported in some myoepitheliomas [6, 9]. However, EWSR1 and FUS rearrangements were absent in this tumor. The 
Table 1 Immunohistochemical results of myoepithelioma-like tumor of the vulvar region

\begin{tabular}{|c|c|c|c|c|}
\hline Antibody & Clone & Dilution & Source & $\overline{\text { Result }}$ \\
\hline$\overline{C K}$ & AE1/AE3 & $1: 100$ & Zhongshan china & - \\
\hline CD34 & $10 C 9$ & $1: 100$ & Zhongshan china & - \\
\hline S-100 & $4 C 4.9$ & Ready-to-use & Maixin China & - \\
\hline GFAP & UMAB129 & $1: 100$ & Zhongshan china & - \\
\hline SMA & $1 \mathrm{~A} 4$ & Ready-to-use & Maixin China & - \\
\hline MyOD1 & MX049 & Ready-to-use & Maixin China & - \\
\hline Myogenin & F5D & Ready-to-use & Maixin China & - \\
\hline INI1 & 25 & $1: 20$ & Zhongshan china & - \\
\hline ER & SP1 & $1: 300$ & Gene & + \\
\hline Calponin & CALP & Ready-to-use & Maixin China & + \\
\hline Calponin & EP63 & Ready-to-use & Zhongshan china & + \\
\hline vimentin & UMAB159 & $1: 100$ & Zhongshan china & + \\
\hline $\mathrm{BCl} 2$ & MX022 & Ready-to-use & Maixin China & + \\
\hline CD99 & $\mathrm{HO} 36-1.1$ & $1: 50$ & Zhongshan china & + \\
\hline EMA & E29 & Ready-to-use & Maixin China & + \\
\hline CD31 & UMAB30 & $1: 100$ & Zhongshan china & - \\
\hline $\mathrm{KI}-67$ & UMAB107 & $1: 100$ & Zhongshan china & $10 \%$ \\
\hline DESMIN & EP15 & $1: 100$ & Zhongshan china & - \\
\hline MUC4 & $8 \mathrm{G7}$ & $1: 100$ & Zhongshan china & - \\
\hline sox10 & EP268 & $1: 100$ & Zhongshan china & - \\
\hline B-catenin & UMAB15 & $1: 100$ & Zhongshan china & - \\
\hline CK7 & OV-TL12/30 & Ready-to-use & Maixin China & - \\
\hline CD117 & YR145 & Ready-to-use & Maixin China & - \\
\hline
\end{tabular}

differential diagnosis of MELTVR also includes extraskeletal myxoid chondrosarcoma (EMC) due to its uniform, loosely cohesive tumor cells in a myxoid matrix. EMC is an extremely rare subtype of vulvar sarcoma that is consistently positive for vimentin, variable positivity for S100 protein, neuron-specific enolase and synaptophysin, completely negative for CK [10-16], and harhor EWSR1-NR4A3 fusion in about $65 \%$ of cases [17]. However, the present case showed S100 negativity, EMA, ER positivity, and EWSR1 was intact showed by FISH assay. Nevertheless, INI1/SMARCB1 expression has been retained in most EMC cases [18, 19], while the loss of INI1/ SMARCB1 gene has also been reported in EMCs without major fusion gene transcript [18].

Due to the loss of expression of the INI1/SMARCB1, MELTVR need to be differentiated from INI1/ SMARCB1-deficient vulvar neoplasms, including epithelioid sarcoma and extrarenal malignant rhabdoid tumor (E-MRT) [20-24]. Epithelioid sarcoma is a malignant tumor, which is divided into classical type of epithelioid sarcoma and proximal type of epithelioid sarcoma. The classical type of epithelioid sarcoma is often located in dermis. The tumor cells are relatively bland epithelioid cells, often showing a "granuloma-like" pattern of necrosis, which is easily misdiagnosed as rheumatoid nodules or annular granulomas [25]. The proximal type of epithelioid sarcoma typically shows a much greater degree of nuclear pleomorphism, more frequent rhabdoid cytology, and geographic necrosis [26], in contrast to the uniform nuclei and amphophilic cytoplasm of MELTVRs. Both forms of epithelioid sarcoma typically coexpress CAM5.2, AE1/AE3, EMA, CK19, vimentin and are CD34 positive in 50 to $70 \%$ of cases $[27,28]$. However, AE1/AE3 and CD34 were completely negative in our case. E-MRT is a highly malignant small round cell tumor that occurs in infants and children. Cellular atypia was easily observed, and mitotic activity was high. E-MRT is extremely aggressive tumor, patients with this tumor often have a short survival $[29,30]$. Unlike EMRT, most MELTVRs occur in adult women, and the majority of MELTVRs showed an indolent clinical
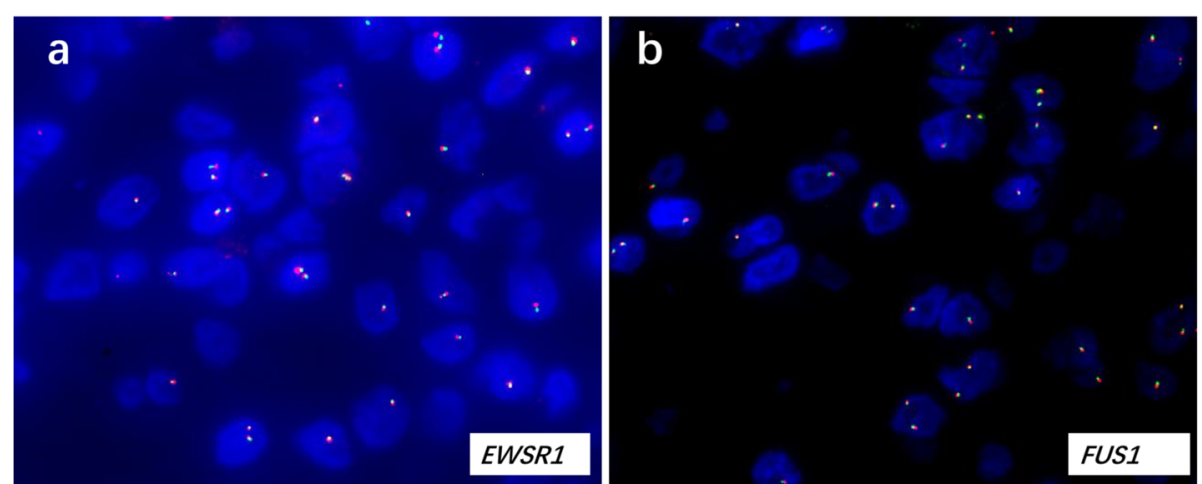

Fig. 3 FISH results of present case. The tumor cells exhibited two pairs of fused signals by (a) EWSR1 and (b) FUS1 probes, no split signals were identified 
Table 2 Summary of clinical and immunohistochemical findings of previously reported and present cases of MELTVRs

\begin{tabular}{|c|c|c|c|c|c|c|c|c|c|c|c|c|c|c|}
\hline \multirow[t]{2}{*}{ Author } & \multirow[t]{2}{*}{ Age } & \multirow[t]{2}{*}{ Size $(\mathrm{mm})$} & \multicolumn{9}{|c|}{ Immunohistochemical findings } & \multirow[t]{2}{*}{ R } & \multirow[t]{2}{*}{ M } & \multirow{2}{*}{$\begin{array}{l}\text { Prognosis } \\
\text { (month) }\end{array}$} \\
\hline & & & $\overline{E R}$ & EMA & GFAP & S-100 & CD34 & INI1 & AE1/AE3 & SMA & Desmin & & & \\
\hline Yoshida [1] & $24-65$ & $20-77$ & + & + & - & - & - & - & $2 / 9^{*}$ & $5 / 8^{*}$ & NA & $3 / 9$ & - & 1to172(mean,66) alive \\
\hline Kaku [2] & 31 & 20 & + & + & - & - & - & - & $+^{* *}$ & - & NA & - & - & $11 \mathrm{~m}$ alive \\
\hline Kojima [3] & 70 & 36 & $+^{* *}$ & + & - & - & - & - & - & + & - & - & - & $12 \mathrm{~m}$ alive \\
\hline Present & 65 & 55 & + & + & - & - & - & - & - & - & - & - & - & $8 \mathrm{~m}$ alive \\
\hline
\end{tabular}

NA data not available; *Rare (<1\%); **Focal (1 to $30 \%) . R$ Recurrence; $M$ Metastasis

course. Immunohistochemically, E-MRT expressed AE1/ AE3, CAM5.2, EMA and vimentin. Vimentin exhibited paranuclear globular staining, which was not observed in MELTVRs. In the present case, epithelioid cells with rhabdomyoblasts-like features in myxoid area was observed, which is needed to be differentiated from embryonal rhabdomyosarcoma (ERMS). However, ERMS is a highly malignant tumor with cellular atypia and a number of mitotic figures. Immunohistochemically, ERMS expresses SMA, desmin, MyoD1 and Myogenin, which are absent in MELTVRs.

The clinical and immunohistochemical features of the reported 11 cases and our case are summerized in Table 2. There is limited information regarding the incidence rate of MELTVRs due to its rarity. Immunohistochemically, there are no specific markers for this neoplasm, but the tumor cells are consistently positive for EMA and ER. All reported cases showed loss of INI1/ SMARCB1 expression, which appears to be a key factor to define the classification of this disease. In the present case, calponin was expressed both in the cytoplasm and in the nucleus of the tumor cells. We analyzed the phenomenon using two different clonal antibodies and the results are consistent. In addition, the present case showed a large number of rhabdomyoblasts-like cells which is not described. FISH analyses were negative for the presence of a rearrangement of the FUS1 and EWSR1 gene in our case. Biologically, all patients of reported cases survive without metastases, while three cases recurred after intralesional excision. Thus, we speculated that most of MELTVR showed an indolent clinical course. Our report is an important supplement to the morphology spectrum of MELTVR.

\section{Conclusion}

Based on previous reports and our observation, these tumors with low-grade malignant features and no metastases, wide excision and tumor-free margins seem to be an appropriate treatment. In summary, we have reported a rare case of MELTVR. Further investigation is required to clearly determine the pathological, immunohistochemical and molecular features of this tumor.

\section{Abbreviations}

CK: Cytokeratin; CT: Computed tomography; EMA: Epithelial membrane antigen; EMC: Extraskeletal myxoid chondrosarcoma; E-MRT: Extrarenal malignant rhabdoid tumor; ER: Estrogen receptor; ERMS: Embryonal rhabdomyosarcoma; FISH: Fluorescence in situ hybridization;

MELTVR: Myoepithelioma-like tumor of the vulvar region; NSE: Neuronspecific enolase; Syn:synaptophysin; SMA: Smooth muscle actin; WHO: World Health Organization

\section{Acknowledgements \\ None.}

\section{Authors' contributions}

$X Y$ performed the histological and immunohistochemical evaluation as well as collected clinical data and drafted the manuscript. GH carried out the molecular genetic studies. GJL read and approved the final manuscript.

\section{Funding}

No funding has been gained by the authors for this research.

Availability of data and materials

All data generated or analyzed during this study are included in this published article.

Ethics approval and consent to participate

This case study was approved by the Institutional Review Board for ethical committee of Tongji University Shanghai East Hospital.

\section{Consent for publication}

The patient gave his written consent for image and data publication.

\section{Competing interests}

The authors declare that they have no competing interests.

Received: 16 August 2019 Accepted: 27 December 2019

Published online: 08 January 2020

References

1. Yoshida A, Yoshida H, Yoshida M, et al. Myoepithelioma-like tumors of the vulvar region: a distinctive group of SMARCB1-deficient neoplasms. Am J Surg Pathol. 2015;39(8):1102-13.

2. Kaku Y, Goto K, Kabashima K. Myoepithelioma-like tumor of the vulvar region presenting as a Nonmyxoid spindle-cell neoplasm: a potential histologic mimicker of solitary fibrous tumor. Am J Dermatopathol. 2016; 38(7):e87-9.

3. Kojima Y, Tanabe M, Kato I, et al. Myoepithelioma-like tumor of the vulvar region showing infiltrative growth and harboring only a few estrogen receptor-positive cells: a case report. Pathol Int. 2019;69(3):172-6.

4. Fletcher CDMBJ, Hogendoorn PCW, et al. WHO classification of Tumours of soft tissue and bone. Lyon: IARC Press; 2013.

5. Folpe AL, Schoolmeester JK, McCluggage WG, et al. SMARCB1deficient vulvar neoplasms: a Clinicopathologic, Immunohistochemical, 
and molecular genetic study of 14 cases. Am J Surg Pathol. 2015; 39(6):836-49.

6. Antonescu CR, Zhang L, Chang NE, et al. EWSR1-POU5F1 fusion in soft tissue myoepithelial tumors. A molecular analysis of sixty-six cases, including soft tissue, bone, and visceral lesions, showing common involvement of the EWSR1 gene. Genes Chromosomes Cancer. 2010; 49(12):1114-24.

7. Brandal P, Panagopoulos I, Bjerkehagen B, et al. Detection of a t(1;22)(q23; q12) translocation leading to an EWSR1-PBX1 fusion gene in a myoepithelioma. Genes Chromosomes Cancer. 2008;47(7):558-64.

8. Brandal P, Panagopoulos I, Bjerkehagen B, Heim S. T(19;22)(q13; 12$)$ translocation leading to the novel fusion gene EWSR1-ZNF444 in soft tissue myoepithelial carcinoma. Genes Chromosomes Cancer. 2009: 48(12):1051-6.

9. Puls F, Arbajian E, Magnusson L, Douis H, Kindblom LG, Mertens F. Myoepithelioma of bone with a novel FUS-POU5F1 fusion gene. Histopathology. 2014;65(6):917-22.

10. Khan AS, Bakhshi GD, Shaikh A, Khan AA, Khan AA, Chitale A. Extraskeletal chondrosarcoma of labium majus. Case Rep Pathol. 2011; 2011:429562

11. Santacruz MR, Proctor L, Thomas DB, Gehrig PA. Extraskeletal myxoid chondrosarcoma: a report of a gynecologic case. Gynecol Oncol. 2005;98(3): 498-501.

12. Sawada M, Tochigi N, Sasajima Y, Hasegawa T, Kasamatsu T, Kitawaki J. Primary extraskeletal myxoid chondrosarcoma of the vulva. J Obstet Gynaecol Res. 2011;37(11):1706-10.

13. Villert A, Kolomiets L, Vasilyev N, Perelmuter V, Savenkova O. Extraskeletal myxoid chondrosarcoma of the vulva: a case report. Oncol Lett. 2015;10(4): 2095-9.

14. Hisaoka M, Hashimoto H. Extraskeletal myxoid chondrosarcoma: updated clinicopathological and molecular genetic characteristics. Pathol Int. 2005; 55(8):453-63.

15. Okamoto S, Hisaoka M, Ishida T, et al. Extraskeletal myxoid chondrosarcoma: a clinicopathologic, immunohistochemical, and molecular analysis of 18 cases. Hum Pathol. 2001;32(10):1116-24.

16. Oliveira AM, Sebo TJ, McGrory JE, Gaffey TA, Rock MG, Nascimento AG. Extraskeletal myxoid chondrosarcoma: a clinicopathologic, immunohistochemical, and ploidy analysis of 23 cases. Mod Pathol. 2000; 13(8):900-8.

17. Nishio J, Iwasaki H, Nabeshima K, Naito M. Cytogenetics and molecular genetics of myxoid soft-tissue sarcomas. Genet Res Int. 2011;2011:497148.

18. Kohashi K, Oda Y, Yamamoto $H$, et al. SMARCB1/INI1 protein expression in round cell soft tissue sarcomas associated with chromosomal translocations involving EWS: a special reference to SMARCB1/INI1 negative variant extraskeletal myxoid chondrosarcoma. Am J Surg Pathol. 2008;32(8):1168-74.

19. Le Loarer F, Zhang L, Fletcher CD, et al. Consistent SMARCB1 homozygous deletions in epithelioid sarcoma and in a subset of myoepithelial carcinomas can be reliably detected by FISH in archival material. Genes Chromosomes Cancer. 2014;53(6):475-86.

20. Hollmann TJ, Hornick JL. INI1-deficient tumors: diagnostic features and molecular genetics. Am J Surg Pathol. 2011;35(10):e47-63.

21. Hornick JL, Dal Cin P, Fletcher CD. Loss of INI1 expression is characteristic of both conventional and proximal-type epithelioid sarcoma. Am J Surg Pathol. 2009;33(4):542-50.

22. Orrock JM, Abbott JJ, Gibson LE, Folpe AL. INI1 and GLUT-1 expression in epithelioid sarcoma and its cutaneous neoplastic and nonneoplastic mimics. Am J Dermatopathol. 2009;31(2):152-6.

23. Hoot AC, Russo P, Judkins AR, Perlman EJ, Biegel JA. Immunohistochemical analysis of hSNF5/INI1 distinguishes renal and extra-renal malignant rhabdoid tumors from other pediatric soft tissue tumors. Am J Surg Pathol. 2004;28(11):1485-91.

24. Judkins AR. Immunohistochemistry of INI1 expression: a new tool for old challenges in CNS and soft tissue pathology. Adv Anat Pathol. 2007;14(5): 335-9.

25. Enzinger FM. Epitheloid sarcoma. A sarcoma simulating a granuloma or a carcinoma. Cancer. 1970;26(5):1029-41.

26. Guillou L, Wadden C, Coindre JM, Krausz T, Fletcher CD. "proximal-type" epithelioid sarcoma, a distinctive aggressive neoplasm showing rhabdoid features. Clinicopathologic, immunohistochemical, and ultrastructural study of a series. Am J Surg Pathol. 1997;21 (2):130-46.
27. Laskin WB, Miettinen M. Epithelioid sarcoma: new insights based on an extended immunohistochemical analysis. Arch Pathol Lab Med. 2003;127(9): $1161-8$

28. Folpe AL. Selected topics in the pathology of epithelioid soft tissue tumors. Mod Pathol. 2014;27(Suppl 1):S64-79.

29. Beckwith JB, Palmer NF. Histopathology and prognosis of Wilms tumors: results from the first National Wilms' tumor study. Cancer. 1978;41(5): 1937-48.

30. Haas JE, Palmer NF, Weinberg AG, Beckwith JB. Ultrastructure of malignant rhabdoid tumor of the kidney. A distinctive renal tumor of children. Hum Pathol. 1981;12(7):646-57.

\section{Publisher's Note}

Springer Nature remains neutral with regard to jurisdictional claims in published maps and institutional affiliations.
Ready to submit your research? Choose BMC and benefit from:

- fast, convenient online submission

- thorough peer review by experienced researchers in your field

- rapid publication on acceptance

- support for research data, including large and complex data types

- gold Open Access which fosters wider collaboration and increased citations

- maximum visibility for your research: over $100 \mathrm{M}$ website views per year

At BMC, research is always in progress.

Learn more biomedcentral.com/submissions 